\title{
Assistance and Support of Primary Caregivers through an eService Platform
}

\author{
Claudia I. Martínez-Alcalá 1,2*, José A. Ramírez-Salvador ${ }^{3}$, Alejandra Rosales-Lagarde 1,2, \\ Brenda Jiménez-Rodríguez ${ }^{1}$
}

\author{
1 Área Académica de Gerontología. Instituto de Ciencias de la Salud, UAEH. Pachuca, Hidalgo, MEXICO \\ ${ }^{2}$ Cátedras-CONACyT. Consejo Nacional de Ciencia y Tecnología, MEXICO \\ 3 Area Académica de Computación y Electrónica. Instituto de Ciencias Básicas e Ingeniería UAEH. Pachuca, Hidalgo, \\ MEXICO
}

\section{*Corresponding Author: cimartinezal@conacyt.mx}

Citation: Martínez-Alcalá, C. I., Ramírez-Salvador, J. A., Rosales-Lagarde, A. and Jiménez-Rodríguez, B. (2018). Assistance and Support of Primary Caregivers through an eService Platform. Journal of Information Systems Engineering \& Management, 3(1), 09. https://doi.org/10.20897/jisem.201809

Published: February 13, 2018

\begin{abstract}
The increasing human longevity around the world calls for new attention models in which the primary caregiver plays a crucial role as a source of care supply. However, primary caregivers' lack of training, along with high levels of stress, depression and anxiety, can have a negative impact on both the caregiver's health and the development of caregiving duties. Hence, the objective of the present article is to introduce the eCuidador platform, an innovative tool that seeks to provide assistance and support to primary caregivers by means of a variety of services available in the cloud with the aim of improving caregivers' health and quality of life. Likewise, we present the results obtained from the pilot test validation, in which the evaluation of the following parameters was carried out: Usability (12), Functionality (10), Design (11), Usefulness (12) and Satisfaction (12). The participants of this pilot test were 12 primary caregivers ( $91.66 \%$ women).
\end{abstract}

Keywords: primary caregiver, assistance, e-services, caregiver overload

\section{INTRODUCTION}

Scientific advances and the development of different branches of medical science have caused a deformation in the population pyramid, leading to a higher proportion of advanced-age population (Christensen et al., 2009). Nevertheless, progress in the field of Information and Communication Technologies (ICT) has allowed the development of a wide array of platforms and technological applications oriented towards assisting and supporting the healthcare field (Yanga et al., 2015; Lee Ventola, 2014). These technological advances enable the systematization, dissemination and socialization of information with the aim of providing timely and effective attention, monitoring and tracking, as they can eliminate accessibility barriers and high costs, especially in vulnerable groups (Lee Ventola, 2014; Haluzaa and Jungwirtha, 2015).

Regarding the significant elderly population growth, it is important to consider that the aging-related lifestyle changes lead to increased health vulnerability in this group of people, which makes them become progressively dependent on others to carry out daily life activities. Thus, elderly adults, especially dependent ones, require the aid of a family member or caregiver to respond to their needs and to provide them the necessary cares (Heller et al., 2015). To this respect, the caregiving role assumed by family members of elderly adults brings about changes in different spheres of a caregiver's life, e.g. family, social life, work, and economy, usually generating negative repercussions on their health and self-care. 
In many cases, the cares provided by the primary caregiver exceed their physical and mental capacities, often causing chronical fatigue known as caregiver overload or Burnout Syndrome (Bello Pineda, 2014; Flores et al., 2014).

According to Rodríguez Otero (Rodríguez Otero, 2016), this syndrome consists of a plurisymptomatic clinical picture that tends to have a significant impact on every sphere of the individual's life. However, not only should the negative effects on the caregiver's health be considered, but also the impact of an overloaded caregiver on the quality and consistency of the assistance provided to the dependent elderly.

Social support networks can be considered an important resource to address this problem, since they play a mediating role that significantly reduces the perceived impact of a stressful and demanding situation. Likewise, these networks represent a primary support system in which social, emotional and informative services are provided according to the receptors' needs and their situational context. Their importance lies in that they seek to promote the receptors' wellbeing and quality of life (elderly adult, family members, caregivers). Nonetheless, these face-to-face programs are often inaccessible to primary caregivers due to the demands of time and attention required by the elderly (Wittenberg-Lyles et al., 2014).

For their part, ICT has been described as a valuable tool to offer several strategies which can constitute support networks and provide a support system with more tracking capacities. They can also allow the integration of connections through means of communication and online support, facilitating permanent interactions among primary caregivers, family members and healthcare systems (Martínez-Alcalá et al., 2013; Martínez-Alcalá et al., 2016).

The authors Haluzaa and Jungwirtha (Haluzaa and Jungwirtha, 2015) posit that the support and assistance provided by ICTs are established by means of web platforms and social networks sharing common objectives. Similarly, social networks established by these mediums work as integration tools where varied sectors are involved (academic, scientific, technological and cultural), in order to support processes, share experiences and strengthen knowledge collectively or individually.

According to the previous statement, it seems necessary to generate interventions in the healthcare field that focus on the primary caregiver. Given the value of ICTs in providing assistance support and access to online support networks, this article presents the eCuidador platform, an online environment that aims at providing assistance and support to primary caregivers through a variety of services available in the cloud, which can contribute to the improvement of their health and quality of life.

The article consists of the following sections: section I corresponds to an introduction of the context in which this project is situated; section II mentions the online assistance services addressed to primary caregivers; section III describes the functionality of the eCuidador platform, as well as the technology used; section IV presents the results obtained from the pilot test validation of the eCuidador platform; finally, section $\mathrm{V}$ deals with conclusions and further research.

\section{ONLINE ASSISTANCE SERVICES AIMED AT PRIMARY CAREGIVERS}

The important introduction of ICTs in the healthcare field has created a significant demand of supporting tools for primary caregivers. For this reason, a documentation and theoretical review process was carried out to gather information on online assistance services developed for primary caregivers (See Table 1).

The findings of former studies suggest the need for generating tools that integrate a variety of assistance and support services for primary caregivers, since most of the services described only tackled a single sphere of the caregiver's life.

\section{METHODS AND MATERIALS}

\section{eCuidador Platform}

The methodological model adopted for the development of eCuidador was the User Centered Design (UCD) approach. This methodology has been widely accepted for the creation of usable applications and/or systems aiming at satisfying the general and specific needs of users (Martínez-Alcalá et al., 2013) (See Figure 1). Alongside this, the technology used for the development of eCuidador was a collaborative platform called SharePoint Server (Microsoft product). This technology allows the system to be easy to use, to be accessed through mobile devices and to have visibility of the resources any time and through any device.

It is important to point out that the development of this platform required the support of a multidisciplinary teamwork composed of gerontologists, nurses, psychologists and engineers. Likewise, the opinions of users, i.e. caregivers, were taken into account during the design and development of the web solution. 
Table 1. Online assistance services

\begin{tabular}{|c|c|c|c|}
\hline Services & Technology & Users & Results \\
\hline $\begin{array}{l}\text { UnderstAID } \\
\text { (Núñez-Naveira et } \\
\text { al., 2016) }\end{array}$ & ICT mobile platfor & $\begin{array}{l}\text { Informal caregivers of } \\
\text { the patients with } \\
\text { dementia }\end{array}$ & $\begin{array}{l}\text { After using UnderstAID the caregivers in the experimental group } \\
\text { significantly decreased their depressive symptomatology according to the } \\
\text { Center for Epidemiologic Studies Depression scale, but a possible benefit } \\
\text { on their feelings of competence and satisfaction with the caring experience } \\
\text { was also observed. }\end{array}$ \\
\hline $\begin{array}{l}\text { SmartCARE } \\
\text { (Adinolfi et al., } \\
\text { 2016) }\end{array}$ & ICT Platform & $\begin{array}{l}\text { Family Caregivers of } \\
\text { patients affected by } \\
\text { stroke diseases }\end{array}$ & $\begin{array}{l}\text { The system provides a set of tools that enable the continuity of care at } \\
\text { home to patients affected by stroke diseases. Moreover, by taking } \\
\text { advantage of motion sensing-based serious games and virtual companions, } \\
\text { the system can stimulate the patient at being more reactive both at neuro- } \\
\text { motorial and neuro-cognitive levels. }\end{array}$ \\
\hline $\begin{array}{l}\text { Online and onsite } \\
\text { training (Lai et al., } \\
\text { 2016) }\end{array}$ & Website & $\begin{array}{l}\text { Caregivers of elders } \\
\text { with dementia }\end{array}$ & $\begin{array}{l}\text { To investigate the effectiveness of a home-based caregiver training } \\
\text { program for caregivers of elders with dementia and behavioral problems. }\end{array}$ \\
\hline $\begin{array}{l}\text { Telephone } \\
\text { intervention (Grant } \\
\text { et al., 2002) }\end{array}$ & Telephony & $\begin{array}{l}\text { Family Caregivers of } \\
\text { Survivors of Stroke }\end{array}$ & $\begin{array}{l}\text { Participants were able to potentiate vitality, mental health, problem-solving } \\
\text { skills and care preparation, and decreased negativity, impulsivity, lack of } \\
\text { self-care and depression related to the burden of the caregiver's role }\end{array}$ \\
\hline $\begin{array}{l}\text { Monitoring } \\
\text { Support (Williams } \\
\text { et al., 2012) }\end{array}$ & Video monitoring & $\begin{array}{l}\text { Family caregivers of } \\
\text { patients with dementia }\end{array}$ & $\begin{array}{l}\text { Professionals reported the value of video recordings for identifying } \\
\text { antecedents and evaluating caregiver responses. The caregiver reported } \\
\text { improved communication and behavior management and ease of use. }\end{array}$ \\
\hline $\begin{array}{l}\text { Internet } \\
\text { intervention (Blom } \\
\text { et al., 2013) }\end{array}$ & Internet/Website & $\begin{array}{l}\text { Caregivers of patients } \\
\text { with dementia }\end{array}$ & $\begin{array}{l}\text { This study will provide evidence about the effectiveness and cost- } \\
\text { effectiveness of an internet intervention for caregivers. If both can be } \\
\text { shown, this might set the stage for the development of a range of internet } \\
\text { interventions in the field of caregiving for people with dementia. This is } \\
\text { even more important because future generations of caregivers will be more } \\
\text { familiar with the use of internet. }\end{array}$ \\
\hline
\end{tabular}

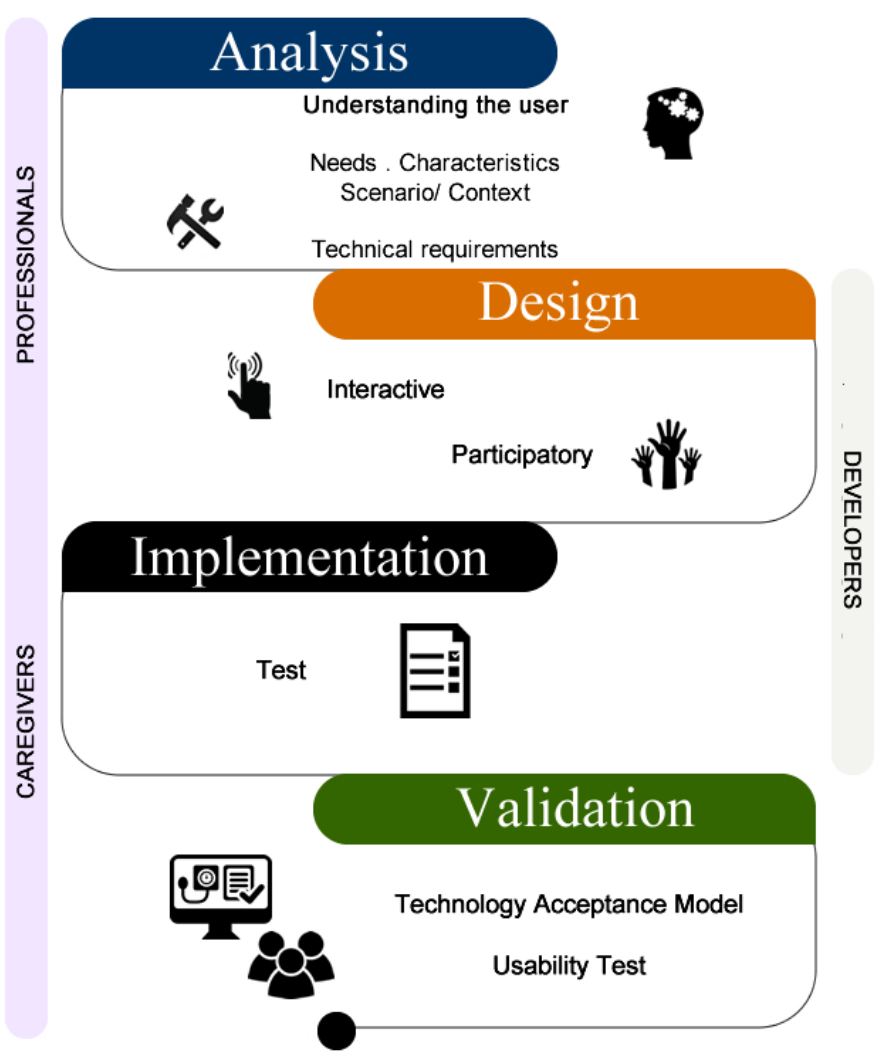

Figure 1. User centered design (UCD) approach

\section{Functionality of eCuidador}

The objective of the eCuidador platform is to provide assistance and support to primary caregivers by means of a variety of services available in the cloud, which can contribute to the improvement of this population's health and quality of life. An important characteristic of eCuidador is that it allows the user to access the system anytime, anywhere, and using any kind of mobile device with Internet access. This last requirement is realized with the adoption of responsive design, which allows redirecting and locating elements from the web service so that they 
visually adapt to different devices, providing an improved user experience. Among the services provided by the platform we can mention:

a) Virtual workshop system: This service offers programs and workshops to primary caregivers of dependent people and/or elderly adults so that they carry out their tasks as efficiently as possible. Moreover, it includes a blog that creates a connection among caregivers, and in which similar cases are stored and discussed in real-time open forums, supervised by specialized personnel (See Figure 2).

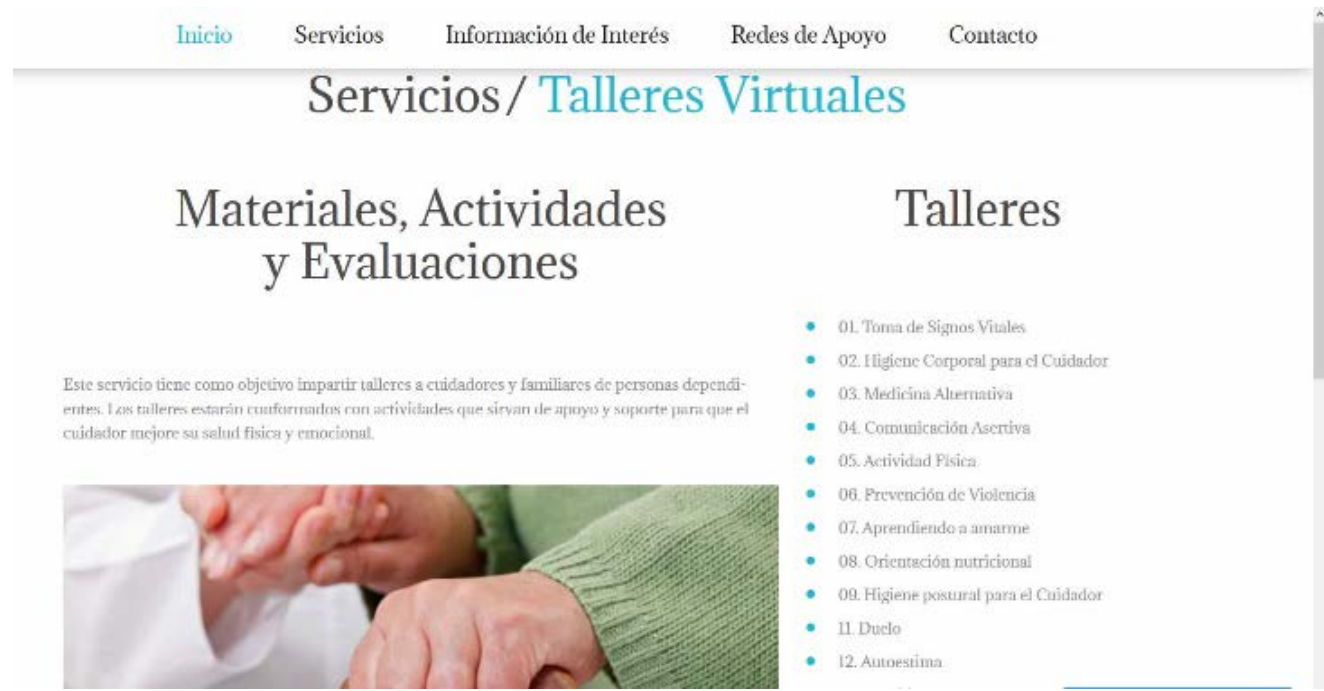

Figure 2. General page of the virtual workshops

b) Therapentic assistance system: The aim of this service is to provide orientation to family members and/or primary caregivers responsible for dependent elderly adults, so that caregivers improve their emotional wellbeing and personal development. Furthermore, this service promotes primary caregiver mental health care by raising awareness on the effects of the caregiver syndrome (See Figure 3).

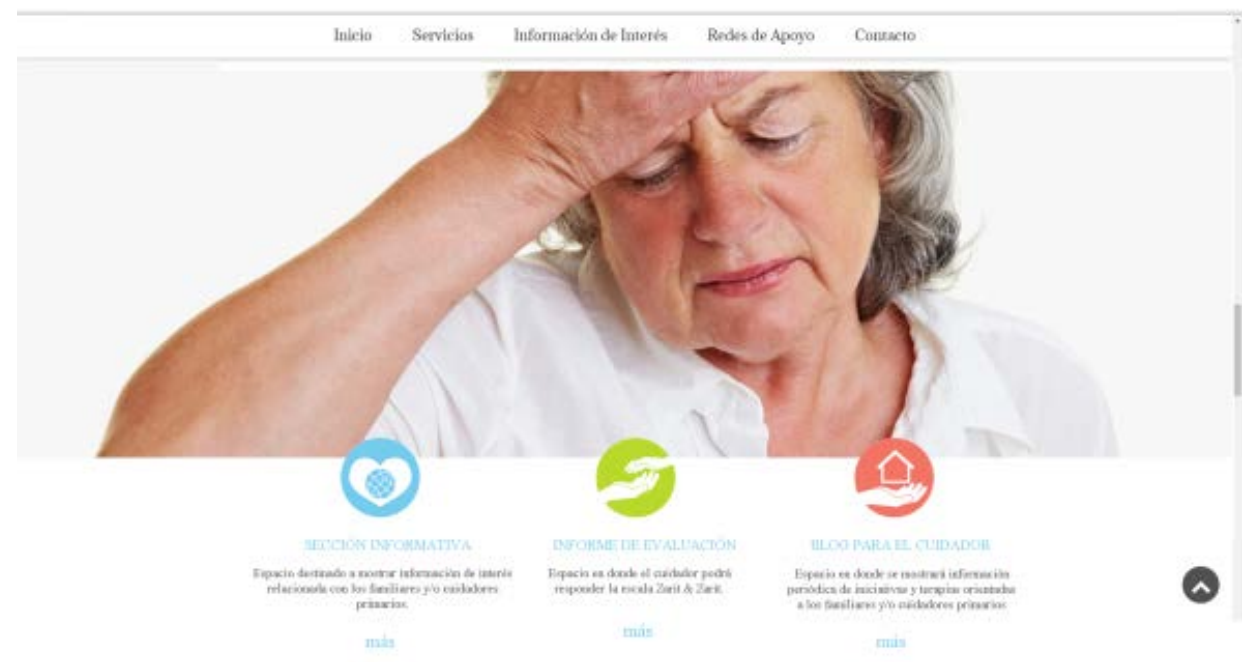

Figure 3. Main page of the Therapeutic Assistance System

c) Social support networks: This service offers information on different support networks and it allows the primary caregiver to identify institutions and/or organizations providing support to this group of people (See Figure 4). 


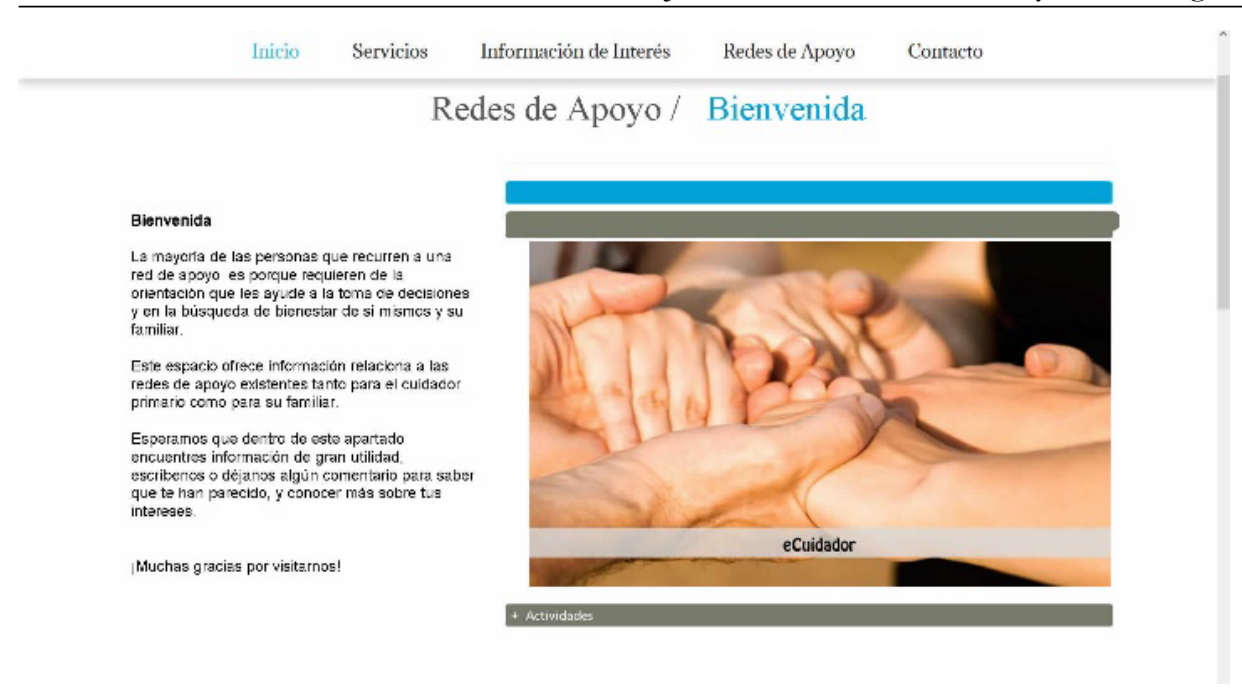

Figure 4. Main page of the Social Support Networks

Every service provided by this platform works 24 hours a day, 365 days a year. For this project, some profiles were designed, but they can also be extended in the future:

- Family members and/or primary caregivers: People responsible for the totality of cares needed by elderly adults or dependent patients, and with whom they have certain personal relationship. They would be the main users of the information provided by the platform.

- Therapists/psychologists: They are in charge of providing the necessary information related to the mental and emotional health of primary caregivers. Hence, this profile can visualize the progress of caregivers or communicate with them individually.

- Gerontologists: They are in charge of providing the necessary information regarding the cares needed by elderly adults or dependent patients, as well as offering holistic assistance programs for primary caregivers.

- Administrator: This profile is responsible for the maintenance of appropriate platform functioning.

\section{VALIDATION}

In order to adequately evaluate the pertinence of the eCuidador platform it was necessary to analyze its usefulness, functionality and design with the main users, so as to detect existing failures and to establish the concrete benefits provided by this platform.

\section{Characteristics of the Population}

From the 12 caregivers who participated in the validation, $91.66 \%$ (11) were women. Regarding age, 66.66\% (8) of the participants were between 36 and 59 years old, and the average age was 43, 2 years old. Also, $83.33 \%$ (10) of the participants were dedicated to household duties. Finally, most of the cares were provided by couples $(41.6 \%)$ and children $(33.3 \%)$ and to a lesser extent by siblings $(16.6 \%)$ and other family members $(8.3 \%)$.

\section{Pilot Test Results}

Upon registration, the 12 caregivers were invited to answer a questionnaire on aspects such as design, usability and technological acceptance ${ }^{1}$. The questionnaire consisted of 15 closed questions and the average response time was of approximately 20 minutes.

The platform validation involved the evaluation of the following parameters: a) usability, b) functionality, c) design, d) usefulness and e) satisfaction. The rating scale used in the questionnaire corresponded to a 5 point Likert scale. Options in the scale were as follows: totally agree (5), agree (4), neutral (3), disagree (2) and totally disagree (1).

In the analysis of the first parameter, usability, users provided unanimous positive response (12), asserting that the eCuidador platform is easy to use and thus navigation between pages is dynamic and intuitive. The fact that this parameter was positively evaluated reveals that the implementation of this kind of services is beneficial not only for caregivers but also for other profiles that would be in need of assistance.

\footnotetext{
${ }^{1}$ Technological acceptance evaluates a series of factors that influence the patient's decision on how and when to use the technology
} 
Regarding the second parameter, functionality, users indicated a positive agreement (10), stating that the eCuidador platform presents minimal errors (which will be corrected in the near future) but that these do not prevent objectives to be accomplished.

The evaluation of the third parameter, design, also indicated a positive agreement (11), which reflects that the design of the eCuidador platform is user-friendly, clear and attractive.

For its part, the usefulness parameter obtained a unanimous positive result (12), which demonstrates the need for creating more systems of this kind.

Finally, the fifth parameter, satisfaction, received a totally favorable result from users (12), which indicates that the eCuidador platform offers an attractive environment for assisting and supporting primary caregivers, allowing them to improve their health and quality of life (See Figure 5).

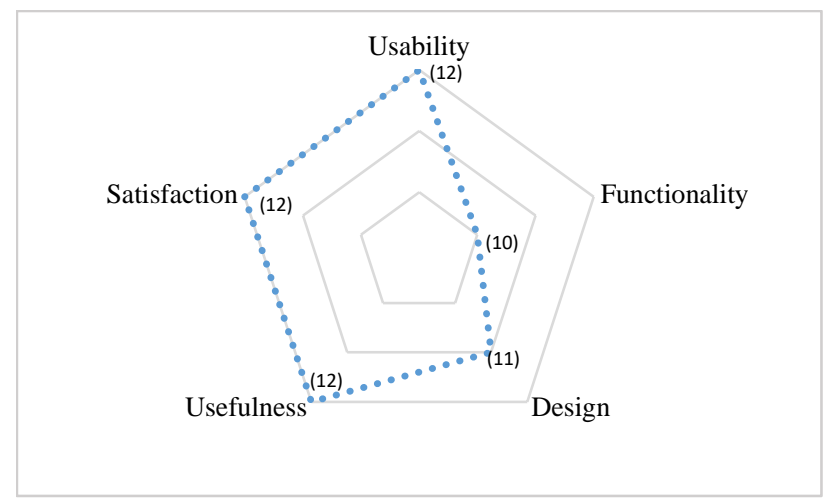

Figure 5. Pilot test results (platform validation)

\section{CONCLUSIONS}

Primary caregivers play a critical role in providing attention to elderly adults and dependant patients. However, caregivers are often affected by episodes of stress, anxiety and depression due to lack of support and counselling for carrying out caregiving duties. Consequently, primary caregivers require the creation of assistance tools that allow them to reduce their overload and improve their quality of life.

The eCuidador platform was created with the idea of providing assistance and support to primary caregivers by means of a variety of services available in the cloud. These services can allow caregivers to improve their health and quality of life, since the platform offers them: a) training and counselling programs and workshops on caregiving duties; b) documentation and activities to improve their emotional wellbeing; c) programs for the caregiver's mental healthcare and awareness raising on the possible effects of the primary caregiver syndrome; and d) the creation of support networks to assist the primary caregiver in the identification of institutions and organizations that provide support to this group of people.

From the results of the platform validation we can conclude that the services offered by eCuidador are potentially capable of providing counselling and training support to caregivers in a more versatile manner and with more coverage, facilitating the permanent interaction among caregivers. Likewise, we believe that this solution can be a viable strategy for caregivers to take better care of themselves and of the people they are in charge of, without suffering economical, emotional and/or moral burden.

Further research will involve the integration of additional assistance services for the caregiver with the aim of providing them with more services such as medical and nutritional counselling, among others.

\section{ACKNOWLEDGEMENT}

The present work has been sponsored by the Consejo Nacional de Ciencia y Tecnología (the National Council of Science and Technology, CONACyT) through the Cátedras CONACyT program and it was carried out within the facilities of the Área Académica de Gerontología del Instituto de Ciencias de la Salud, Universidad Autónoma del Estado de Hidalgo (UAEH).

The authors wish to thank the Elderly Adult Attention Institute of the State of Hidalgo (IAAMEH, Instituto de atención para las y los adultos mayores del Estado de Hidalgo), especially to Psych. Patricia Padilla-Muñoz for her support in the planning of the thematic areas developed in the platform 


\section{REFERENCES}

Adinolfi, F., Caggianese, G., Gallo, L., Grosso, J., Infarinato, F., Marchese, N., ..., Spaltro, E. (2016). SmartCARE_-An ICT platform in the domain of stroke pathology to manage rehabilitation treatment and telemonitoring at home. In Intelligent Interactive Multimedia Systems and Services, 55, 39-49. (Smart Innovation, Systems and Technologies, 55). Springer Science and Business Media Deutschland GmbH. https://doi.org/10.1007/978-3-319-39345-2_4

Blom, M., Bosmans, J., Cuijpers, P., Zarit, S. and Pot, A. (2013). Effectiveness and cost-effectiveness of an internet intervention for family caregivers of people with dementia: design of a randomized controlled trial. BMC Psychiatry, 13(17). https:/ / doi.org/10.1186/1471-244X-13-17

Christensen, K., Doblhammer, G., Roland, R. and W Vaupel, J. (2009). Ageing populations: the challenges ahead. Lancet, 374(9696), 1196-1208. https:// doi.org/10.1016/S0140-6736(09)61460-4

Flores, N., Jenaro, C., Moro, L. and Tomsa, R. (2014). Health and quality of life of family caregivers and professionals of dependent elderly people: A comparative study. Europan Journal of Investigation in Health, 4(2), 79-88. https://doi.org/10.1989/ejihpe.v4i2.55

Grant, J., Elliott, T., Weaver, M., Bartolucci, A. and Giger, J. (2002). Telephone intervention with family caregivers of stroke survivors after rehabilitation. Stroke, 33(8), 2060-2065. https://doi.org/10.1161/01.STR.0000020711.38824.E3

Haluzaa, D. and Jungwirtha, D. (2015). ICT and the future of health care: aspects of health promotion. International Journal of Medical Informatics, 84(1), 48-57. https:/ / doi.org/10.1016/j.ijmedinf.2014.09.005

Heller, T., Gibbons, H.M. and Fisher, D. (2015). Caregiving and Family Support Interventions: Crossing Networks of Aging and Developmental Disabilities. American Association on Intellectual and Developmental Disabilities, 53(6). https:/ / doi.org/10.1352/1934-9556-53.5.329

Instituto Mexicano del Seguro Social (IMSS, 2014). Primary caregiver overload of patients with chronic degenerative diseases. Sobrecarga del cuidador primario de pacientes con enfermedades crónico degenerativas. Xalapa Veracruz. Disponible en: https://www.uv.mx/blogs/favem2014/files/2014/06/Tesis-gabriela.pdf

Lai, C.K.Y., Wong, L.F., Liu, K.H., Lui, W., Chan, M.F. and Yap, L.S.Y. (2016). Online and onsite training for family caregivers of people with dementia: results from a pilot study. Geriatric Psychiatry, 28(1), 107-108. https://doi.org/10.1002/gps.3798

Lee Ventola, C. (2014). Mobile Devices and Apps for Health Care Professionals: Uses and Benefits. Pharmacy and Therapeutics, 39(5), 356-364.

Martínez-Alcalá, C.I., Muñoz, M. and Monguet-Fierro, J. (2013). Design and Customization of Telemedicine Systems. Computational and Mathematical Methods in Medicine, 2013(Article ID 618025), 16. https://doi.org/10.1155/2013/618025

Martínez-Alcalá, C.I., Pliego-Pastrana, Patricia Rosales-Lagarde, A., Rodríguez-Torres, E.E. and Lopez-Noguerola, J.S. (2016). Training primary caregivers of dependent people through the use of ICT. In Information Systems and Technologies (CISTI), 11th Iberian Conference on (pp. 6). https://doi.org/10.1109/CISTI.2016.7521410

Martínez-Alcalá, C.I., Ramirez-Salvador, J.A., Rosales-Lagarde, A. and Jimenez-Rodríguez, B. (2017). An eService platform for the assistance and support of primary caregivers. In Information Systems and Technologies (CISTI), 12th Iberian Conference on (pp. 1-5). IEEE. https:// doi.org/10.23919/CISTI.2017.7975767

Núñez-Naveira, L., Alonso-Búa, B., de Labra, C., Gregersen, R., Maibom, K., Mojs, E., ..., Millán-Calenti, J.C. (2016). UnderstAID, an ICT Platform to Help Informal Caregivers of People with Dementia: A Pilot Randomized Controlled Study. BioMed Research International, 13. https:/ / doi.org/10.1155/2016/5726465

Rodríguez Otero, L.M. (2016). Burnout Syndrome in family caregivers of depents. International Journal of Asian Social Science, 6(1), 12-20. https:/ /doi.org/10.18488/journal.1/2016.6.1/1.1.12.20

Williams, K., Arthur, A., Niedens, M., Louis, M. and Hutfles, L. (2012). In-Home Monitoring Support for Dementia Caregivers. Clinical Nursing Research, 22(2).

Wittenberg-Lyles, E., Washington, K., Demiris, G., Oliver, D. and Shaunfield, S. (2014). Understanding Social Support Burden among Family Caregivers. Health Communication, 29(9), $901-910$. https://doi.org/10.1080/10410236.2013.815111

Yanga, J.J., Lic, J., Mulderd, J., Wange, Y., Chenf, S., Wug, H., .., Panf, H. (2015). Emerging information technologies for enhanced healthcare. Computers in Industry, 69, 3-11. https://doi.org/10.1016/j.compind.2015.01.012 